\title{
Avaliação das notificações de erros programáticos na administração de imunobiológicos em Porto Alegre - RS, 2019
}

\author{
Evaluation of notifications of programmatic errors in immunobiological administration in \\ Porto Alegre - RS, 2019
}
Evaluación de las notificaciones de errores programáticos en la administración inmunobiológica en Porto Alegre - RS, 2019

Renata Lobatto Capponi ${ }^{1 *}$, Ceura Beatriz de Souza Cunha1, Nicole dos Santos Paz¹.

\begin{abstract}
RESUMO
Objetivo: Avaliar as notificações de erros programáticos na administração de imunobiológicos buscando um maior conhecimento dos eventos relacionados a um procedimento inadequado, reunindo subsídios para os processos de capacitação, atualização e adoção de medidas de prevenção. Métodos: Esse estudo trata-se de uma avaliação quantitativa e descritiva das notificações de erros programáticos realizadas pelos estabelecimentos de saúde no ano de 2019 no município de Porto Alegre. As informações foram retiradas do Sistema de Informação do Programa Nacional de Imunizações (SI-PNI). Resultados: No período do estudo, foram aplicadas 1.223 .896 doses de vacinas e registrados 243 procedimentos inadequados. Entre as notificações, predominaram aquelas ligadas à vacina tríplice viral, tetra viral, hepatite $\mathrm{B}$ e rotavírus. Observouse o predomínio de erros relacionados ao tipo de imunobiológico utilizado $(27,2 \%)$. Conclusão: Verificamos que é de suma importância identificar os erros de imunização e suas causas, visando diminuir os danos gerados por essas ocorrências. Devem ser discutidos, com os profissionais envolvidos nas atividades de vacinação, fatores organizacionais, ambientais e psicológicos, além de promover capacitações com uma maior frequência, a fim de reforçar as informações e atualizá-los das modificações do calendário nacional.
\end{abstract}

Palavras-chave: Enfermagem, Erros de medicação, Esquemas de imunização.

\begin{abstract}
Objective: To evaluate the reports of programmatic errors in the administration of immunobiologicals seeking a greater knowledge of the events related to an inadequate procedure, gathering subsidies for the processes of training, updating and adoption of prevention measures. Methods: This study is a quantitative and descriptive evaluation of the notifications of programmatic errors made by health establishments in 2019 in the city of Porto Alegre. The information was taken from the Information System of the National Immunization Program (SI-PNI). Results: During the study period, 1,223,896 doses of vaccines were administered and 243 inadequate procedures were recorded. Among the notifications, predominated those related to the triple viral vaccine, tetraviral, hepatitis B and rotavirus. There was a predominance of errors related to the type of immunobiological used (27.2\%). Conclusion: We verified that it is of paramount importance to identify immunization errors and their causes, in order to reduce the damages generated by these occurrences. It should be discussed, with professionals involved in vaccination activities, organizational, environmental and psychological factors, in addition to promoting training more frequently, in order to reinforce the information and update them of the modifications of the national calendar.
\end{abstract}

Keywords: Nursing, Medication errors, Immunization regimens.

1 Núcleo de Imunizações - Diretoria Geral de Vigilância em Saúde, Porto Alegre - RS.

*E-mail: renata.capponi@portoalegre.rs.gov.br

SUBMETIDO EM: 8/2020

ACEITO EM: 9/2020

PUBLICADO EM: 10/2020

REAS / EJCH | Vol.12(10) | e4838 | DOI: https://doi.org/10.25248/reas.e4838.2020 Página 1 de 9 


\section{RESUMEN}

Objetivo: Evaluar las notificaciones de errores programáticos en la administración de inmunobiológicos buscando un mayor conocimiento de los eventos relacionados a un procedimiento inadecuado, reuniendo subsidios para los procesos de capacitación, actualización y adopción de medidas de prevención. Métodos: Este estudio se trata de una evaluación cuantitativa y descriptiva de las notificaciones de errores programáticos realizadas por los establecimientos de salud en el año 2019 en el municipio de Porto Alegre. La información se obtuvo del Sistema de Información del Programa Nacional de Inmunizaciones (SI-PNI). Resultados: En el período del estudio, fueron aplicadas 1.223 .896 dosis de vacunas y registrados 243 procedimientos inadecuados. Entre las notificaciones, predominaron aquellas ligadas a la vacuna triple viral, tetra viral, hepatitis B y rotavirus. Se observó la prevalencia de errores relacionados con el tipo de inmunobiológico utilizado $(27,2 \%)$. Conclusión: Constatamos que es de suma importancia identificar los errores de inmunización y sus causas, con el fin de disminuir los daños generados por estos hechos. Deben ser discutidos, con los profesionales involucrados en las actividades de vacunación, factores organizativos, ambientales y psicológicos, además de promover capacitaciones con mayor frecuencia, a fin de reforzar las informaciones y actualizarlas de las modificaciones del calendario nacional.

Palabras clave: Enfermería, Errores de medicación, Esquemas de inmunización.

\section{INTRODUÇÃO}

O Programa Nacional de Imunizações (PNI) foi criado em 1973 com o objetivo de organizar a política nacional de vacinação. Ao longo dos anos consolidou-se como uma relevante estratégia de Saúde Pública, contribuindo para redução da morbidade e mortalidade por doenças imunopreveníveis, bem como para diminuição de custos com consultas e internações hospitalares (JUNIOR JBS, 2013).

Atualmente, o PNI oferta 43 produtos que contemplam vacinas, soros e imunoglobulinas e dentre suas atribuições está à compra, distribuição e controle de qualidade dos imunobiológicos, organização das campanhas nacionais de vacinação, capacitações e atualizações, além da realização da vigilância de eventos adversos pós-vacinação e erros de imunização (BRASIL, 2014a; JUNIOR JBS, 2013).

Os erros de imunização ou erros programáticos são eventos inusitados que advém de alguma falha ou erro em procedimentos no preparo ou administração de imunobiológicos como: dose, via, local, idade e/ou vacina.

Conceitualmente, um erro de medicação é qualquer evento evitável que pode causar ou levar a um uso inapropriado de medicamentos, incluindo todos os imunobiológicos, ou causar dano a um paciente, enquanto estão sob o controle de profissionais de saúde, paciente ou consumidores (BRASIL, 2014b).

A partir da verificação da ocorrência de um erro ou falha é importante conhecermos o fluxo de notificação de erros programáticos e as condutas que devem ser realizadas após essa detecção. De acordo com BRITO MCM, et al. (2019) as seguintes condutas devem ser tomadas: averiguar as circunstâncias e os detalhes do evento; relatar o ocorrido na ficha de notificação de erros programáticos; informar o cliente de que o caso será investigado e acompanhado; programar seguimento clínico 1 vez por semana por um período de 30 dias; acompanhar o caso até o encerramento do monitoramento; fornecer, ao final, orientações e condutas recomendadas quanto a continuidade ou não do esquema vacinal.

Para evitar que esses acontecimentos ocorram é fundamental que as vacinas sejam utilizadas conforme a sua indicação, dosagem, via de administração, armazenamento e procedimentos descritos em bula, sempre considerando suas contraindicações. O cumprimento das normas e técnicas contribui significativamente para redução dos erros em imunização e ignorá-las ou desrespeitá-las pode ocasionar prejuízo ou inexistência do efeito almejado, além de eventos adversos graves e até fatais (BRASIL, 2014b). 
Em razão disso, a figura do profissional enfermeiro é fortemente relevante, pois ele é considerado o responsável pelo gerenciamento do serviço de imunização, atuando nos cuidados com a rede de frio, notificação de eventos adversos pós-vacinais, administração de imunobiológicos, gestão do sistema de informação, organização de campanhas, na busca ativa e a educação continuada, auxiliando assim, para evitar e minimizar os erros em imunização. Esses processos, da mesma forma, devem envolver na prática do seu cotidiano, a orientação efetiva dos pacientes e familiares e a monitorização da qualidade das vacinas aplicadas (TRINDADE AA, et al., 2019).

Logo, somente realizar a notificação desses erros não é o suficiente, sendo necessária uma vigilância e avaliação dos dados para que se obtenha um maior conhecimento dos eventos relacionados a um procedimento inadequado, reunindo subsídios para os processos de capacitação, atualização e adoção de medidas de prevenção. É válido destacar que uma vigilância detalhada busca preconizar as práticas de atenção e promoção da saúde dos cidadãos, além de fortalecer os mecanismos adotados para prevenção de doenças (BRITO MFP, et al., 2014).

Sendo assim, esse estudo tem como objetivo avaliar as notificações de erros programáticos na administração de imunobiológicos notificadas no ano de 2019, no município de Porto Alegre. Vale ressaltar que em nossa literatura são encontrados poucos trabalhos sobre esse assunto, sendo necessário um número maior de estudos que abordam e discutem essa temática.

\section{MÉTODOS}

O território de Porto Alegre tem uma população de 1.409.351 habitantes distribuída em 17 Distritos Sanitários (DS). Esses distritos possuem limites geográficos e população definidos de acordo com o estabelecimento dos serviços a serem ofertados, ou seja, são regionalizados. No Estado do Rio Grande do Sul, Porto Alegre integra a $10^{\underline{a}}$ Região de Saúde, a 2 ${ }^{\underline{a}}$ Coordenadoria Regional de Saúde e a Macrorregião Metropolitana (PREFEITURA MUNICIPAL DE PORTO ALEGRE, 2017).

Atualmente, o setor de imunizações realiza a entrega de imunobiológicos para 135 salas públicas de vacinação, 14 salas localizadas em serviços hospitalares e um Centro de Referência em Imunobiológicos Especiais (CRIE). Esses serviços são responsáveis pelo preenchimento das fichas de notificação de erros programáticos e o envio dessas fichas para a Vigilância em Saúde. O Núcleo de Imunizações, que faz parte da Equipe de Vigilância de Doenças Transmissíveis, avalia e digita as fichas no Sistema de Informação do Programa Nacional de Imunizações (SI-PNI).

O SI-PNI constitui-se um notável recurso de gestão, gerando informações que servem para o planejamento, organização e tomada de decisão das instâncias federais, estaduais e municipais. O sistema disponibiliza dados inerentes às ações de vacinação e cria informações individualizadas, aprimorando a qualidade de informações do indivíduo vacinado, contemplando a notificação das vacinas agendadas e em atraso e realizando a vigilância de eventos adversos pós-vacinação e erros programáticos (SILVA BS, et al.,2018). Os profissionais da instância estadual confirmam o erro, após a inserção das informações no sistema e orientam as condutas a serem seguidas em cada caso. O Núcleo de Imunizações repassa esse retorno para o estabelecimento de saúde que realizou a notificação, que deve entrar em contato com usuário envolvido e instruí-lo de acordo com o orientado.

Este artigo trata de uma avaliação quantitativa e descritiva das notificações de erros programáticos realizadas pelos estabelecimentos de saúde no ano de 2019 no município de Porto Alegre, RS. A pesquisa utilizou somente dados secundários, não sendo necessária a aprovação pelo Comitê de Ética em Pesquisa (CEP), conforme a Resolução 510 de 2016 do Conselho Nacional de Saúde. Essa resolução estabelece que estudos com bancos de dados, cujas informações são agregadas, sem possibilidade de identificação individual, não serão registradas e nem avaliadas pelo CEP.

Para a sua realização, as informações foram extraídas do SI-PNI, sendo separadas em quatro categorias e tabuladas em uma planilha, utilizando-se o software Microsoft Excel® 2010: tipo de imunobiológico administrado, estabelecimento de saúde onde ocorreu o erro, classificação do erro e ocasião do erro. 
Foram consideradas as vacinas que estão atualmente disponíveis nas estratégias de rotina e campanha: antirrábica, pentavalente, tríplice bacteriana adulto (DTP), dupla adulto (dT), tríplice bacteriana acelular (dTpa), febre amarela, hepatite B, hepatite A, rotavírus, HPV, pneumo 10, pneumo 13, pneumo 23, poliomielite oral (VOP) e injetável (VIP), tríplice viral, tetra viral, varicela, meningo $\mathrm{C}$ e influenza trivalente.

A classificação do erro foi dividida em sete tipos de procedimentos inadequados: erros de prescrição (fora da idade recomendada e erro de indicação); erros de administração (via de administração, dosagem e diluição incorretas); validade vencida (utilização de vacinas fora do prazo de validade); intervalo inadequado entre as vacinas; não avaliação das contraindicações; tipo de imunobiológico utilizado (troca de imunobiológicos na aplicação) e Outros (abscesso quente e duplicidade de doses).

Dados como a via de administração dos imunobiológicos (oral, subcutânea, intramuscular), evolução (cura, sequela e óbito) e a classificação final do evento (leve ou grave) também foram avaliadas neste período.

\section{RESULTADOS}

No período do estudo, foram aplicadas 1.223 .896 doses de vacinas e registrados 243 procedimentos inadequados, correspondendo a aproximadamente 20 erros para cada mil doses aplicadas. Entre as notificações, predominaram aquelas ligadas à vacina tríplice viral $(26,7 \%)$, tetra viral $(18,5 \%)$, hepatite $B$ $(9,5 \%)$, rotavírus $(7,8 \%)$, meningo $\mathrm{C}(7,0 \%)$ e tríplice bacteriana $(7,0 \%)$ (Tabela 1$)$.

Tabela 1 - Distribuição dos erros de imunização notificados, de acordo com o imunobiológico utilizado no município de Porto Alegre, 2019.

\begin{tabular}{lll}
\hline Imunobiológicos & Procedimentos inadequados (n) & $\%$ \\
\hline Tríplice Viral & 65 & 26,7 \\
Tetra viral & 45 & 18,5 \\
Hepatite B & 23 & 9,5 \\
Vacina Oral de Rotavírus Humano & 19 & 7,8 \\
Meningocócica C conjugada & 17 & 7,0 \\
Tríplice Bacteriana & 17 & 7,0 \\
Pentavalente & 13 & 5,3 \\
Febre amarela & 6 & 2,5 \\
Pneumocócica 10 valente & 6 & 2,5 \\
Vacina Antirrábica Humana & 5 & 2,1 \\
BCG & 5 & 2,1 \\
Papiloma Vírus Humano & 4 & 1,6 \\
Vacina Oral Poliomielite & 4 & 1,6 \\
Tríplice Bacteriana Acelular Adulto & 4 & 1,6 \\
Influenza Trivalente & 4 & 1,6 \\
Dupla Adulto & 3 & 1,2 \\
Hepatite A (pediátrica) & 2 & 0,8 \\
Varicela & 1 & 0,4 \\
\hline Total & $\mathbf{2 4 3}$ & $\mathbf{1 0 0 , 0}$
\end{tabular}

Fonte: Capponi RL, et al., 2019; dados extraídos do Sistema Nacional do Programa Nacional de Imunizações (SIPNI).

Ao avaliarmos a distribuição dos procedimentos inadequados observamos o predomínio dos eventos relacionados à administração de vacinas fora da idade preconizada (28,8\%), tipo de imunobiológico utilizado $(27,2 \%)$, seguidos de validade vencida (18,5\%) e não avaliação das contraindicações (9,5\%) (Tabela 2 ). 
Tabela 2 - Distribuição do número de procedimentos inadequados na administração de imunobiológicos $(\mathrm{n}=243)$ no ano de 2019, Porto Alegre, RS.

\begin{tabular}{lll}
\hline Tipo de erro & $\mathbf{n}$ & \% \\
\hline Erros de prescrição ou indicação (fora da idade recomendada) & 70 & 28,8 \\
Tipo de Imunobiológico utilizado & 66 & 27,2 \\
Validade vencida & 45 & 18,5 \\
Não avaliação de contraindicações ou precauções & 23 & 9,5 \\
Erros de técnica de administração & 19 & 7,8 \\
Intervalo inadequado entre vacinas & 15 & 6,2 \\
Outros & 5 & 2,1 \\
\hline Total & $\mathbf{2 4 3}$ & $\mathbf{1 0 0}$ \\
\hline
\end{tabular}

Fonte: Capponi RL, et al., 2019; dados extraídos do Sistema Nacional do Programa Nacional de Imunizações (SIPNI).

Quando analisamos o número de erros de imunizações por sala de vacina, constatamos que das 150 salas de imunizações do município, 60 não realizaram nenhuma notificação durante o ano de 2019. Dos 90 serviços que tiveram notificações, a sala $E$ teve o maior número dessas ocorrências, sendo a responsável por 9,5\% dos acontecimentos, seguida da sala M (Tabela 3). Àqueles que notificaram entre 1 e 3 erros foram aglutinados e classificados como "Demais unidades". Nessa situação foram encontrados 74 estabelecimentos de saúde que apresentaram 123 erros programáticos.

Tabela 3 - Número de procedimentos inadequados na administração de imunobiológicos, por sala de vacinas ( $\mathrm{n}=90)$. Porto Alegre, Rio Grande do Sul, 2019.

\begin{tabular}{cll}
\hline Unidades & Procedimentos Inadequados (n) & $\%$ \\
\hline B & 7 & 2,9 \\
C & 6 & 2,5 \\
D & 5 & 2,1 \\
E & 23 & 9,5 \\
F & 5 & 2,1 \\
G & 8 & 3,3 \\
H & 11 & 4,5 \\
I & 6 & 2,5 \\
J & 6 & 2,5 \\
K & 4 & 1,6 \\
L & 4 & 1,6 \\
M & 17 & 7,0 \\
N & 4 & 1,6 \\
O & 4 & 1,6 \\
P & 6 & 2,5 \\
Q & 4 & 1,6 \\
Demais unidades & 123 & 50,6 \\
\hline Total & $\mathbf{2 4 3}$ & $\mathbf{1 0 0}$
\end{tabular}

Fonte: Capponi RL, et al., 2019; dados extraídos do Sistema Nacional do Programa Nacional de Imunizações (SIPNI).

Quanto à ocasião do procedimento inadequado, verificou-se que 187 notificações ocorreram na estratégia rotina (77\%) e 56 durante as Campanhas Nacionais de Vacinação (23\%) (Tabela 4). Vale ressaltar que durante $\mathrm{o}$ ano de 2019, o município de Porto Alegre realizou três campanhas. A primeira delas ocorreu nos 
meses de abril e maio e teve como objetivo a imunização contra a Influenza, contemplando os grupos que são considerados prioritários para o Ministério da Saúde, definido em nota técnica. A segunda e a terceira ação, visou proteger a população contra o Sarampo, no período de outubro e novembro, priorizando as crianças de 6 meses a menores de cinco anos e os adultos entre 20 e 29 anos, respectivamente. Durante essas três campanhas foram aplicadas 637.742 doses de imunobiológicos.

Tabela 4 - Distribuição do número de procedimentos inadequados na administração de imunobiológicos $(\mathrm{n}=243)$ por estratégia de vacinação no ano de 2019, Porto Alegre, RS.

\begin{tabular}{lcc}
\hline Tipo de estratégia & $\mathbf{n}$ & $\%$ \\
\hline \multicolumn{1}{c}{ Rotina } & 187 & 77 \\
Campanha & 56 & 23 \\
\hline Total & 243 & 100
\end{tabular}

Fonte: Capponi RL, et al., 2019; dados extraídos do Sistema Nacional do Programa Nacional de Imunizações (SIPNI).

$\mathrm{Na}$ análise da via de administração, foram encontrados os seguintes resultados: 117 erros em aplicações subcutâneas (48,1\%), 98 pela via intramuscular $(40,3 \%), 23$ oral $(9,4 \%)$ e 5 aplicações intradérmicas $(2,0 \%)$. Todos os eventos (100\%) tiveram como evolução a cura e na classificação final foram considerados como eventos leves.

\section{DISCUSSÃO}

Ao avaliarmos as notificações dos procedimentos inadequados relacionados à administração de imunobiológicos no município de Porto Alegre - RS, no ano de 2019, percebemos que a maioria dos serviços de saúde notificou algum tipo de falha no momento da vacinação, com ocorrência predominantemente na estratégia rotina $(77 \%)$.

Considerando o tipo de unidade notificadora, encontramos as unidades públicas de vacinação como as responsáveis pelo maior número de notificações, apresentando um total de $89,6 \%$, seguida das notificações feitas pelos hospitais $(9,4 \%)$ e pelo Centro de Referência de Imunobiológicos Especiais (1\%). Esse resultado está associado a um maior número de unidades de saúde e à grande quantidade de administração de imunobiológicos que esses serviços realizam. Destacamos que apesar do CRIE ser uma referência no atendimento de pacientes que possuem condições clínicas especiais e complexas, também houve a ocorrência de erros programáticos nesse local.

Os imunobiológicos com maior número de envolvimento nestes erros, foram as vacinas tríplice viral e tetra viral, associadas principalmente com a administração fora da idade recomendada, diferentemente dos dados encontrados por Rodrigues IS, et al. (2012), que em seu estudo detectou o predomínio de erros com a vacina contra Influenza.

No entanto, no relato de Folgearini GF (2017), observamos que os eventos mais frequentes derivaram da vacina contra poliomielite oral (VOP) $(20,8 \%)$ e pentavalente $(12 \%)$, relacionados à administração do imunobiológico com validade vencida (27\%) em decorrência da desatenção do vacinador $(62,5 \%)$.

Observamos que os erros associados à vacina tríplice viral, que protege contra sarampo, caxumba e rubéola, podem ser atribuídos à inclusão da dose zero adotada no ano do estudo. Essa dose é indicada de acordo com a situação epidemiológica de cada local, ou seja, é realizada em períodos em que ocorre a circulação viral do sarampo. Ela deve ser administrada na faixa etária de 6 meses até 11 meses e 29 dias, não sendo considerada como dose válida para o esquema de imunização contra as doenças que protege. $O$ objetivo é diminuir a incidência e gravidade dessa doença nos menores de um ano de idade (BRASIL, 2019).

Durante o ano de 2019, foram aplicadas 1.223 .896 doses de vacinas e registrados 243 procedimentos inadequados, correspondendo a aproximadamente 20 erros para cada mil doses aplicadas. Essa prevalência é maior do que a descrita no artigo de Brito MFP, et al. (2014) que encontrou o equivalente a 9 procedimentos 
incorretos a cada mil doses aplicadas em notificações realizadas entre os anos de 2007 à 2012 no município de São Paulo.

Acreditamos que a alta diferença entre as prevalências deve-se ao fato de que nos anos anteriores o sistema de informação utilizado pelo Ministério da Saúde não possuía as ferramentas que possui hoje, proporcionando uma melhor avaliação dos dados digitados e gerando relatórios que auxiliam na realização da vigilância dos erros programáticos. Também, destacamos que a prevalência pode ser maior do que a encontrada, considerando que nem sempre os procedimentos inadequados são notificados. Segundo Santos JC e Ceolim MF (2009) somente $25 \%$ dos casos de erros de medicação são comunicados aos responsáveis, na maioria das vezes por medo da punição, ou em outros casos, vergonha.

Sobre a avaliação do número de eventos notificados por sala de vacinação observamos que a sala $E$ é responsável por cerca de $9,5 \%$ dos eventos. Isso se deve ao fato do serviço funcionar como referência de imunização no município de Porto Alegre e alguns municípios vizinhos, o que leva ao atendimento de uma demanda maior do que as demais salas. Essa constatação corrobora com o descrito na pesquisa de Andriolo MW, et al. (2015), que reconhece em seu estudo, que fatores como a variedade de imunobiológicos oferecidos, a grande procura pela população, a semelhança entre os frascos dos produtos e a falta de atenção e capacitação dos profissionais que atuam nas salas de vacinação, podem induzir a diversos erros.

Nas notificações analisadas, evidenciamos uma maior frequência nas vacinas pertencentes ao calendário de rotina, quando comparamos com o número de erros associados à estratégia campanha. Essa análise acaba divergindo do que sugere Rodrigues IS, et al. (2012), que observou que nas ocasiões de campanhas, como por exemplo, a da vacina Influenza, há um aumento significativo desses eventos, devido a uma expressiva sobrecarga de trabalho dos funcionários. Acreditamos que essa divergência esteja ligada à quantidade de doses aplicadas, quando se observa que as aplicações de rotina, são praticamente o dobro do número de doses administradas durante as campanhas.

Sobre a categoria tipos de erros encontrados, notamos que os três incidentes mais comuns foram: erros de prescrição ou indicação (fora da idade recomendada), tipo de imunobiológico utilizado e validade vencida. Os dois primeiros acontecem pela falta de conhecimento do que é preconizado no calendário nacional de imunizações, acarretando em doses administradas fora da faixa etária e em desacordo com a idade ou tipo de paciente.

Nas situações em que houve a aplicação de imunobiológicos com a validade vencida, temos como causas a distração e a não observância de princípios básicos da enfermagem como elencados por BRITO MCM, et al. (2019): usuário certo; triagem certa; momento certo; higienização das mãos correta; vacina certa; apresentação e validade certa; seringa e agulha certa; dose certa; via de administração certa; tempo de administração certo e descarte certo.

O autor Dias et al (2014) cita em seu artigo que o primeiro fator para ocorrência de erros é a sobrecarga de trabalho advinda do cansaço dos profissionais, seguida da falta de atenção do profissional, corroborando assim, com os dados encontrados. Ele também, destaca que a sobrecarga é um dos maiores motivos de insatisfação profissional, o que pode aumentar a rotatividade nos serviços de saúde.

Ressaltamos que esses procedimentos poderiam ter sido evitados se fossem seguidas as orientações sobre o fluxo de atendimento preconizado, que estipula a realização dos registros no cartão de vacinação e no sistema de informação (SI-PNI ou E-SUS, de acordo com o estabelecimento), antes da administração do imunobiológico. Essas ferramentas auxiliam o profissional na averiguação dos dados, como faixa etária e também emitem alertas quanto a validade e vacina utilizada.

Os eventos referentes a não avaliação das contraindicações, à técnica de administração, intervalo inadequado entre as vacinas, foram encontrados com uma menor frequência, no entanto, demonstram novamente o desconhecimento sobre os imunobiológicos e a ausência da realização de uma triagem correta. Nos acontecimentos classificados como Outros, embora pouco notificados, observam-se casos de abscessos quentes após a administração dos imunobiológicos, revelando a falha nos cuidados e nas orientações necessárias para uma aplicação segura.

REAS / EJCH | Vol.12(10) | e4838 | DOI: https://doi.org/10.25248/reas.e4838.2020 Página 7 de 9 
Em sua pesquisa Thuong TC, et al. (2017), também encontrou esses dados ao investigar um surto de eventos adversos pós vacinação caracterizados como graves, incluindo um óbito, envolvendo 9 crianças com abscesso no local da aplicação da vacina. Ele identificou algumas práticas inadequadas realizadas pela vacinadora, como a não lavagem das mãos entre os atendimentos, além do manuseio do imunobiológico ou a agulha durante o preparo da dose. Brito MFP, et al. (2014) menciona em seu estudo, que para uma assistência livre de eventos ocasionais, a segurança do paciente deve iniciar pelas informações que devem ser colhidas a seu respeito, contemplando a observação do estado físico e o fornecimento de orientações e esclarecimentos sobre possíveis eventos adversos após a administração da vacina, além do manejo e técnica adequada.

Outros autores também sustentam em seus estudos, que os atores humanos são os principais responsáveis pela ocorrência de erros em imunização. Podemos citar, como exemplo, uma pesquisa realizada no Paraná, por Bisetto LHL e Ciosak SI (2017), que classificou o discurso dos vacinadores sobre erro de imunização em três categorias analíticas: atores humanos (57,3\%), institucionais/organizacionais (34\%) e ambientais (8,7\%). Das categorias empíricas, destacaram-se fatores psicológicos $(43,2 \%)$ e das subcategorias: distração $(21,4 \%)$ e estresse $(20,9 \%)$. Esses dados também denotam a importância de os profissionais envolvidos com as atividades de imunização, seguirem os fluxos e normas recomendadas pelo Ministério da Saúde. Em sua avaliação ficou evidente que abscesso subcutâneo quente pode ter associação com várias vacinas administradas por diferentes vias e com etiologia infecciosa, relacionando-se com o desvio de boas práticas em vacinação no processo realizado, principalmente à falta de higienização das mãos. Foi concluído que na visão dos profissionais, a realização de campanhas, introdução de novas vacinas e mudanças no calendário aumentam os riscos de erros relacionados principalmente a fatores psicológicos e gestão de pessoas.

Sabe-se que a equipe de enfermagem, na maioria dos serviços de saúde avaliados, é a principal responsável pela organização das salas de vacinas e que o profissional técnico de enfermagem assume o papel de vacinador e administrador da sala, observando os cuidados com a administração, com a rede de frio e com os insumos necessários (OLIVEIRA VC, et al., 2013).

Barboza TC, et al. (2020) reforça que todo o processo de trabalho, incluindo a análise dos erros de imunização deve integrar o enfermeiro, melhorando a sua supervisão e oferecendo orientação continuada a sua equipe, visando a redução de danos, além de acompanhar os usuários que buscam os serviços, com o auxílio de protocolos e ferramentas que contribuam positivamente para manutenção da qualidade e confiança ao PNI.

Joaquim FL, et al. (2014) igualmente descreve a importância de um enfermeiro que atua nas salas de vacinas e executa atividades de educação permanente. Entre os principais erros encontrados em sua pesquisa, podemos citar: a não lavagem das mãos, a diluição incorreta do imunobiológico, a delimitação errônea da área de aplicação, a aplicação rápida que pode ser responsável por eventos locais e a contaminação, podendo gerar a formação de abscessos.

Assim, todos esses relatos reforçam a ideia de que os erros de medicação são eventos considerados evitáveis. Mas apesar desse fato, eles podem gerar várias consequências como: ocasionar eventos adversos, necessidade de revacinação, perda da dose por ultrapassar a idade limite para realização do imunobiológico e aplicações não recomendadas. Em nossas avaliações, não foram notificados casos apresentando sequelas ou óbitos e nem classificação final considerada como um evento grave. Contudo, sabemos que esses acontecimentos podem acabar impactando negativamente no Programa Nacional de Imunizações, trazendo a diminuição da confiança da população (já abalada pelas fakes news) incidindo assim, nas coberturas vacinais e no controle, eliminação e erradicação das doenças imunopreveníveis. (BISETTO LHL e CIOSAK SI, 2017).

\section{CONCLUSÃO}

Analisando os eventos notificados percebemos que eles poderiam ter sido evitados se os profissionais da saúde estivessem capacitados e atualizados sobre as rotinas na sala de vacinação. Apesar, de não haverem 
erros classificados como graves, eles possuem consequências ocasionando eventos adversos, necessidade de revacinação e perda da dose por ultrapassar a idade limite para realização do imunobiológico. Por isso, faz-se necessário a realização de uma vigilância adequada com o objetivo de identificar os erros e suas causas, na tentativa de qualificar o atendimento nas ações de vacinação, visando diminuir os danos causados.

\section{REFERÊNCIAS}

1. ANDRIOLO MW, et al. Vigilância dos erros programáticos no processo de imunização nos municípios da $13^{a}$ Coordenadoria Regional de Saúde. Salão de Ensino e de Extensão Universidade de Santa Cruz do Sul, 2015.

2. BARBOZA TC, et al. Estudo retrospectivo dos erros de imunização notificados em um Sistema de Informação online. Revista Latino-Americana de Enfermagem, 2020; 28: e3303.

3. BISETTO LHL, CIOSAK SI. Análise da ocorrência de evento adverso pós vacinação decorrente de erro de imunização. Revista Brasileira de Enfermagem, 2017; 70(1): 87-95.

4. BRASIL. Ministério da Saúde. Manual de Normas e Procedimentos para Vacinação. Secretaria de Vigilância em Saúde. Departamento de Vigilância das Doenças Transmissíveis. Editora do Ministério da Saúde, Brasília, 2014a.

5. BRASIL. Ministério da Saúde. Manual de Vigilância Epidemiológica de Eventos Adversos Pós-vacinação. Secretaria de Vigilância em Saúde. Departamento de Vigilância das Doenças Transmissíveis. 3. ed. Editora do Ministério da Saúde, Brasília, 2014b.

6. BRASIL. Ministério da Saúde. Secretaria de Vigilância em Saúde. Boletim Epidemiológico 12. Volume 50. № 19. Ago. 2019.

7. BRITO MCM, et al. Secretaria Estadual de Saúde de Goiás. Superintendência de Vigilância em Saúde. Gerência de Imunizações e rede de frio. Guia prático de imunizações para trabalhadores da sala de vacinação. 4. ed. Goiás, 2019.

8. BRITO MFP, et al. Caracterização das notificações de procedimentos inadequados na administração de imunobiológicos em Ribeirão Preto, São Paulo, 2007-2012. Epidemiol. Serv. Saúde, 2014; 23(1):33-44.

9. CONSELHO NACIONAL DE SAÚDE. Resolução ํํ 510, de 07 de abril de 2016. Diário Oficial da República Federativa do Brasil, Brasília, 24 maio. 2016. Seção 1, p. 44.

10. DIAS JD, et al. Compreensão de enfermeiros sobre segurança do paciente e erros de medicação. Revista mineira de enfermagem, 2014; 4(18): 866-873.

11. FOLGEARINI GF. Segurança do paciente em imunizações: vacinação segura da teoria à prática. Trabalho de Conclusão de Curso (Curso de Enfermagem) - Repositório Institucional UNISC. Universidade de Santa Cruz do Sul, 2017; $81 \mathrm{p}$.

12. JOAQUIM FL, CAMACHO ACLF. Produção científica sobre os erros na conservação e administração de imunobiológicos: revisão integrativa. Rev. Enferm UFPE on line, 2014; 8(11): 4001-4010.

13. JUNIOR JBS. 40 anos do Programa Nacional de Imunizações: uma conquista da Saúde Pública brasileira. Epidemiol. Serv. Saúde, 2013; 22(1): 7-8.

14. OLIVEIRA VC, et al. Supervisão de enfermagem em sala de vacina: a percepção do enfermeiro. Texto Contexto Enferm, Florianópolis, 2013;22(4): 1015-1021.

15. PREFEITURA MUNICIPAL DE PORTO ALEGRE. Secretaria de Saúde. Plano Municipal de Saúde de Porto Alegre 2018-2021. Porto Alegre: 2017.

16. RODRIGUES IC, et al. Procedimentos inadequados em sala de vacinas: a realidade da região de São José do Rio Preto. Boletim Epidemiológico Paulista (online), 2012; 9(100): 16-28.

17. SANTOS JC, CEOLIM MF. latrogenias de enfermagem em pacientes idosos hospitalizados. Revista da Escola de Enfermagem da Universidade de São Paulo, 2009; 43(4):810-817.

18. SILVA BS, et al. Estudo de avaliabilidade do Sistema de Informação do Programa Nacional de Imunização. Revista Brasileira de Enfermagem. 2018; 71(supl.1):615-624.

19. THUONG TC, et al. An Outbreak of Severe Infections with Community-Acquired MRSA Carrying the Panton-Valentine Leukocidin Following Vaccination. Plos One. 2007; 2(9): e822.

20. TRINDADE AA, et al. As implicações práticas do enfermeiro em saúde da família: um olhar sobre a sala de imunizações. Revista Eletrônica Acervo Saúde. 2019; Vol.Supl.19: e263. 